\title{
SOME RESPIRATORY AND CARDIOVASCULAR PROBLEMS AFTER BIRTH*
}

\author{
BY \\ G. S. DAWES \\ From the Nuffield Institute for Medical Research, University of Oxford
}

It is a privilege to speak in memory of Sir George Frederic Still. Still was born in 1868 . He took a classical degree at Cambridge and studied medicine at Guy's Hospital. In 1897, at the age of 29, when medical registrar and pathologist to The Hospital for Sick Children, Great Ormond Street, he published a paper 'on a form of chronic joint disease in children', an original and accurate description of what became widely known as 'Still's disease'. In 1906, at the age of 38, he became the first Professor of the Diseases of Children in the United Kingdom, at King's College. He spent the rest of his life looking after children, and in the advancement of knowledge of their diseases.

Thirty years ago, in 1928, Still became the first President of the British Paediatric Association. He must already have seen great changes in the practice of medicine, and it would have been hard to believe that there were even more revolutionary advances just ahead. But the years that followed, years of unemployment, of international crisis, and of war, were accompanied by an astonishing tide of medical discoveries. These came partly from the observations of practising physicians, from a better understanding of the natural history of disease. They came partly from fundamental investigations, from the development of chemotherapeutic agents and antibiotics, from advances in anaesthesia and surgical technique, from a host of different investigators all over the world. These discoveries have had a great influence on the expectation of life of children in this country. In Fig. 1 is plotted the total number of deaths, in England and Wales, by age up to 12 years, for 1928 and 1957 . The total number of live births registered were 660,267 in 1928, and 723,381 in 1957. There are several interesting points about these figures. Firstly, there has been a great general improvement in the last 30 years; no elaborate statistics are needed to make this apparent. Secondly, during the first week of life the improve-

* The Still Memorial Lecture presented to the meeting of the British Paediatric Association in Scarborough in April, 1959. ment is very much less than that at subsequent periods. Thus deaths during the first week were $2 \cdot 16 / 1,000$ live births in 1928 ; they were still $1 \cdot 39 / 1,000$ in 1957 . The result is that, in 1957, 10,177 children died from natural causes in the first seven days of life, and only 9,994 during the next seven years. These figures are startling; very similar ones are reported from other countries. The stillbirth rate, which was $22 \cdot 5 / 1,000$ live births in 1957, has remained about the same for the last ten years. There were therefore more than 16,000 stillbirths, as compared with a loss of 10,177 during the first week after birth in 1957.

At or after birth there are, therefore three types of problem which demand attention: (1) Stillbirth;

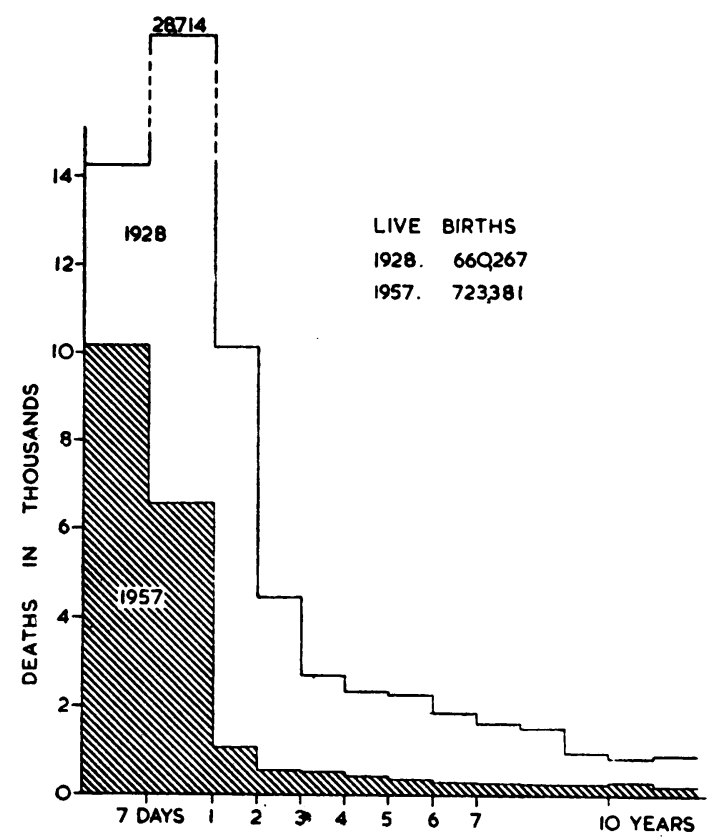

FIG. 1.-The deaths in 1928 and 1957 in England and Wales have been plotted at ages of 0-7 days from birth, 7 days-1 year, and thereafter annually up to 12 years. 
this is an obstetric rather than a paediatric problem. (2) Immaturity, atelectasis and postnatal asphyxia, which together account for more than half neonatal deaths, according to the Registrar-General's tables. We may add hyaline membrane disease to this group. (3) Spastic paralysis, since it is widely believed that asphyxia at birth may be one cause of this condition.

I propose to talk about experiments upon animals in relation to these problems. Animal experiments can be useful in two ways. Firstly it may prove possible to reproduce a disease in experimental animals. For example Ashton and his colleagues were able to cause retrolental fibroplasia by exposing young animals to high $\mathrm{O}_{2}$ concentrations, and hence to incriminate this as an important factor in causing the disease. Sometimes a naturally occurring disease in animals appears very similar to that in man. Thus toxaemia of pregnancy occurs in sheep, and a report has appeared which suggests that hyaline membrane disease may occur in the thoroughbred foal. These provide direct lines of attack upon the diseases in question.

The second way in which animal experiments can help is in providing background knowledge of biological mechanisms. It is about this aspect of research upon the newborn that I propose to talk, and to illustrate by examples. Although a great deal of work has been done over the last 50 years on such fundamental problems as the control of the circulation and breathing, and the effect of changes in the environment of the adult animal and man, very little attention has been paid to the newborn. We therefore have several general biological problems to tackle. Is the small newborn animal in these respects an exact miniature replica of the adult? Or are there features of its physiological behaviour which are peculiar to its size and youth? Some babies are born before the normal period of gestation is ended. They are immature, but what do we mean by immature in quantitative terms? Are their blood pressure and cardiac output less? Can we measure their cardiovascular and respiratory reflexes, and their ability to withstand asphyxia ? Perhaps their physiological behaviour is different, not only in degree, but also in kind, from that of adults? We also have to consider species differences. When a physiological mechanism has been shown to exist in animals, it may be possible to show that it also exists in the baby, and I hope to give examples of this: But I do not mean thereby to suggest that the intellectual traffic is all one way. There are many examples where observations upon the human infant have stimulated research upon animals, often with unexpected results. There are therefore good reasons why paediatricians, physiologists and biochemists should work together in order to tackle the many problems which are of mutual interest.

\section{Changes in the Circulation after Birth}

The changes which take place after birth can be divided into two categories, the anatomical and the functional. I think we are now coming towards the end of a period when the anatomical changes were of predominant interest, and turning towards the functional. This can be illustrated by reference to the change in the circulation from the foetal to the neonatal condition. The work of Barcroft and his colleagues (Barclay, Franklin and Prichard, 1944; Barcroft, 1946) had suggested that the ductus arteriosus and foramen ovale were both closed within a few minutes after the establishment of normal breathing. We now have reason to believe that neither of these changes are normally complete for several days from birth. The most striking evidence with regard to the ductus arteriosus is the presence of a loud murmur in newborn lambs, calves and foals (Dawes, Mott and Widdicombe, 1955 ; Amoroso, Dawes and Mott, 1957), audible on the left side of the chest and radiating medially from the mid-axillary line. This murmur is undoubtedly due to turbulent flow of blood at high pressure from the aorta to the pulmonary trunk, as has been shown by cineangiograms and by measurements of the pressure and oxygen content of blood withdrawn from the great vessels. The murmur is abolished by ligation of the ductus arteriosus. The murmur normally appears within 10-15 minutes of birth and persists for as long as two days. It is only heard when the ductus is partly constricted, though even then as much as half the pulmonary blood flow may be passing through the ductus. There is now ample evidence that in human babies, also, the ductus arteriosus does not close completely and at once after birth. Thus Rowe and James (1957) and Adams and Lind (1957) have taken cineangiograms and catheterized newborn infants; they have calculated that a large proportion of pulmonary flow comes from the ductus arteriosus for several days after birth. The cardiac murmur from a patent ductus arteriosus, which is so easily and so regularly heard in lambs, was not so readily identified in children. It was not until last year that Burnard (1958) in a painstaking and fascinating piece of work, established its presence in more than onethird of human births. It was fascinating because he made the unexpected observation that the murmur in human infants was heard more frequently in association with a history of asphyxia 
and with a raised respiratory rate. We do not yet know what are the full implications of this association, for we still have so little factual information about the cardiovascular and respiratory systems in such infants.

Closure of the valve of the foramen ovale is effected by a change in the pressure relations between the left atrium and the inferior vena cava. In the foetus, blood normally passes from the inferior vena cava to the left atrium, but when ventilation is begun and the cord is tied, pulmonary blood flow increases and umbilical flow ceases. There is therefore a relative rise in left atrial pressure and a fall in inferior vena caval pressure, so that the valve becomes apposed to the foramen ovale during the greater part of the cardiac cycle. Barcroft (1946) concluded that since the blood of a newborn lamb became relatively well saturated with oxygen within a few hours of birth, it was unlikely that much blood passed as a right-to-left shunt through the foramen ovale. Yet the arterial blood of a newborn lamb is not wholly saturated with oxygen, and there was still the possibility of a small right-to-left shunt during a short period of the cardiac cycle only. Lind and Wegelius (1954) reported the passage of small quantities of contrast medium from the inferior vena cava to the left side of the heart in some human babies, but this might have been due to rapid injections of large quantities of contrast medium, which raises the pressure in the great veins. Recently Condorelli, Dagianti, Polosa and Giuliano (1957) have produced evidence of a very small right-to-left shunt in unanaesthetized lambs up to the fifth day from birth, using a dye-dilution method which involved an injection of only $0.2 \mathrm{ml}$. at a time. Weisbrot, James, Prince, Holaday and Apgar (1958) found a mean left atrial $\mathrm{O}_{2}$ saturation of $93 \cdot 8 \pm 2 \cdot 6$ (S.D.) \% (by passing a catheter from the umbilical vein) in 10 normal babies during the first hour of life. Therefore in the normal baby any such shunt must also be very small.

Nevertheless for some days after birth the anatomical pathways which are usually thought of as peculiar to the foetus are still not firmly shut. The reactions of the cardiovascular system after birth are therefore different from those of the adult. Firstly so long as there is a left-to-right shunt through the ductus, from aorta to pulmonary trunk, pulmonary blood flow is increased; this may be of some transient advantage, but the load on the left ventricle is also greater. Heart failure may occur for this reason. Secondly if the baby becomes asphyxiated the direction of blood flow through the ductus may reverse (James and Rowe, 1957) and venous pressure may rise, giving a large right-to-left shunt through the foramen ovale. It is abundantly clear that the neonatal circulation, though only a transitional form between the foetal and adult, requires careful study. It is also interesting that the same general conclusions have been reached from studies on both animals and babies.

\section{Changes in Oxygen Consumption at Birth}

So much for the anatomical side. We now have to consider function, and this is not a matter which can be discussed in isolation. It brings us straightaway to a consideration of size. Small animals have a large surface area relative to their body weight. Since heat loss is proportionate to surface area, the energy production of small mammals must be high, in order to keep their body temperature constant at $37-38^{\circ} \mathrm{C}$. If metabolic rate is relatively high, then the consumption of oxygen, the production of carbon dioxide, respiratory movements and cardiac output are likely to be increased in proportion. These are matters which are almost self-evident; the consequences for the changes which occur after birth are considerable.

The oxygen consumption of a foetal lamb has been estimated by measuring umbilical blood flow and multiplying this by the umbilical arteriovenous oxygen difference. This gives a figure of some $4.5 \mathrm{ml} . / \mathrm{kg} . / \mathrm{min}$. in foetal lambs which have a reasonably high arterial $\mathrm{O}_{2}$ saturation, say $50 \%$ or more. This figure falls within the normal range for the oxygen consumption of adult sheep; that is to say, the normal rate of $\mathrm{O}_{2}$ consumption of the foetus, per unit body weight, is much the same as that of the ewe. But within a day after birth the lamb's resting oxygen consumption, measured directly, increases nearly threefold to a mean of about $12 \mathrm{ml} . / \mathrm{kg} . / \mathrm{min}$. (Dawes and Mott, 1959b, Fig. 2). This change is just about what might be anticipated from theoretical considerations, for the surface area of a newborn lamb is, weight for weight, approximately three times that of an adult sheep. Presumably this increase in oxygen consumption after birth may also occur in species other than the sheep. Some postnatal observations by Mount (1958) suggest that it may take place in piglets, but this is hardly direct evidence. So far there are no reliable estimates of the rate of oxygen consumption of human babies in utero; the newborn baby has an oxygen consumption of only $5-7 \mathrm{ml} . / \mathrm{kg} . / \mathrm{min}$. (Cross, Tizard and Trythall, 1957), but is usually better clothed and kept in a warmer environment than a newborn lamb.

We may here pause to consider the implications of some of these observations. They suggest that before birth the mechanisms are present and ready 


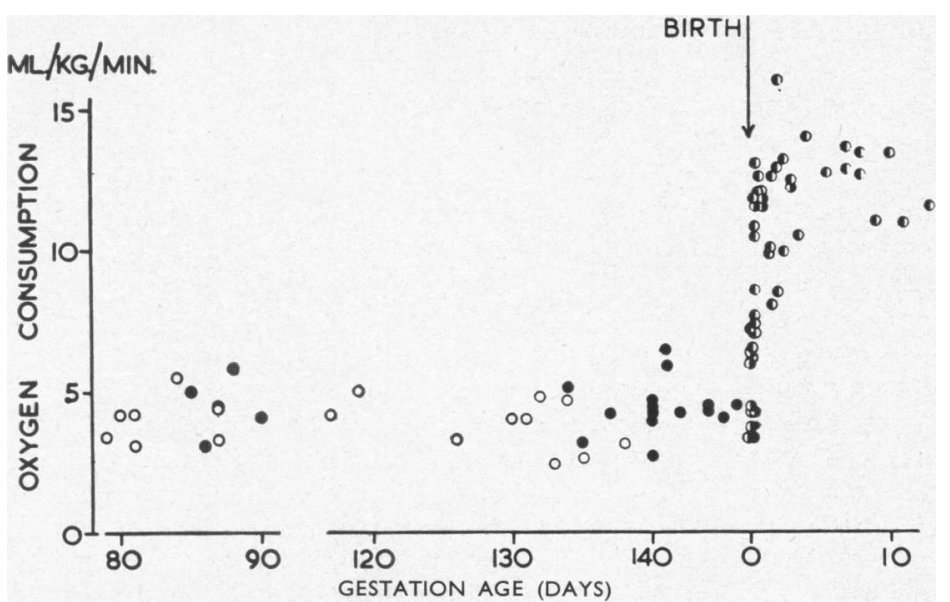

FIG. 2.-The rate of $\mathrm{O}_{2}$ consumption/unit body weight has been plotted against gestation age in days for foetal lambs anaesthetized with pentobarbitone (O) or chloralose (O), and in days from birth in newborn lambs ventilated artificially (O) or breathing spontaneously (D). $\mathrm{O}_{2}$ consumption increases about three-fold after birth (Dawes and Mott, 1959b).

to serve a radical change in metabolism and function. Such subtle matters as the regulation of appetite and of shivering in response to cold, which can hardly have been practised in utero are prepared and ready for use. After a day or two a lamb can maintain its body temperature in a laboratory at $20^{\circ} \mathrm{C}$. without shivering; how this is achieved so rapidly we do not yet know.

\section{Oxygen Consumption and Partial Oxygen Lack in the Newborn}

I now propose to turn to a general consideration of the response to oxygen lack in the newborn. It is important to bear in mind the general opinion of physiologists about this matter, i.e. that in adult mammals, oxygen consumption is independent of the oxygen content of the inspired air, until this is lowered to such an extent that life is seriously endangered. This view the arterial blood of adult man.

was based on the fact that observations on man at high altitude did not suggest that metabolic rate was reduced. It was also supported by acute experiments on adult dogs. Oxygen consumption was not reduced until the arterial $\mathrm{O}_{2}$ saturation fell below $40 \%$, corresponding to $6 \% \mathrm{O}_{2}$ or less in the inspired air. At this point there was evidence of impending cardiovascular failure (Harrison and Blalock, 1927; Cordier and Mayer, 1935; Gorlin and Lewis, 1954). Finally many experiments on isolated enzyme systems have shown that they are able to accept oxygen at very low partial pressures, down to $5 \mathrm{~mm}$. $\mathrm{Hg}$ or less, as compared with a normal partial pressure of $95 \mathrm{~mm} . \mathrm{Hg}$ in

In some species, and under certain conditions, $\mathrm{O}_{2}$ consumption is indeed largely independent of the arterial $\mathrm{O}_{2}$ partial pressure, and Fig. 3 shows such an experiment upon an adult sheep. However, when we turn to small animals, and in particular newborn animals, the results are different. One of the most important contributions in this field was the demonstration by Cross et al. $(1955,1957)$ that when the oxygen content of the inspired air is

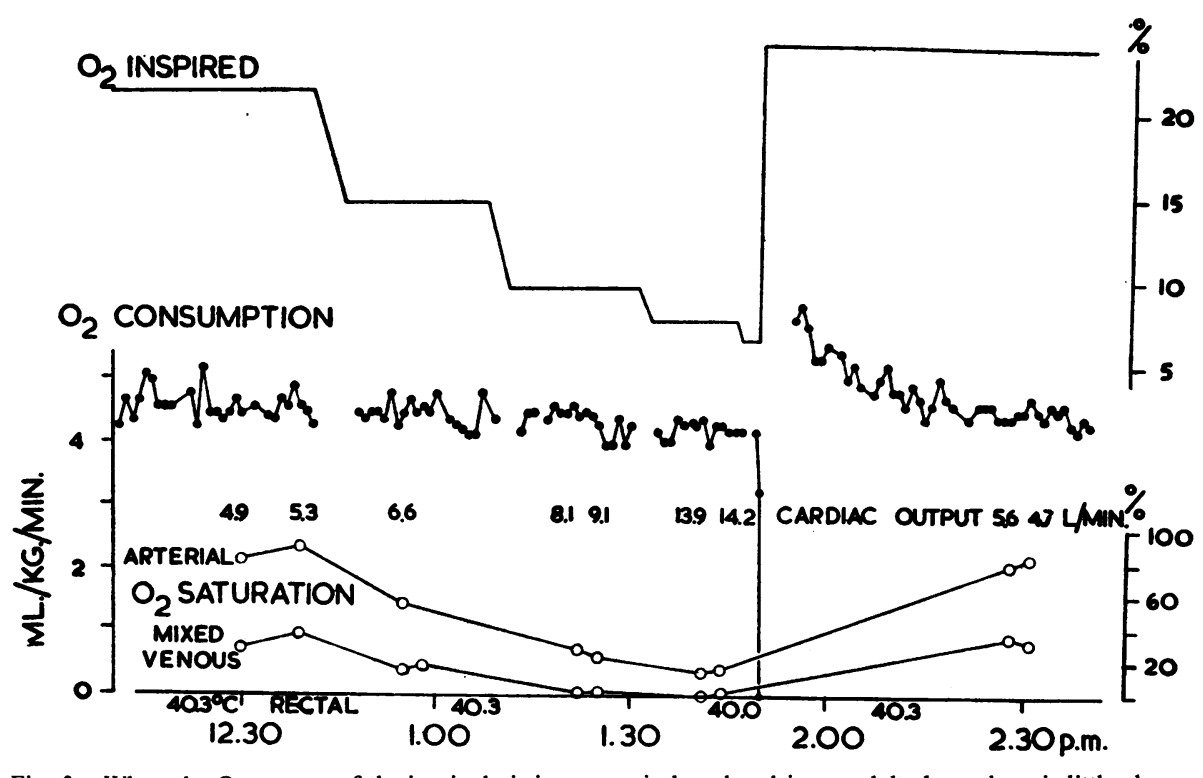

Fig. 3.-When the $\mathrm{O}_{2}$ content of the inspired air is progressively reduced in an adult sheep there is little change in $\mathrm{O}_{2}$ consumption until respiration stops, but cardiac output increases greatly (Cross, Dawes and Mott, 1959). 
reduced, only from $20.9 \%$ to $15 \%$, the rate of oxygen consumption falls in newborn babies. Since that time a similar phenomenon has been demonstrated in the newborn of a number of other species (Fig. 4).

The causes of the failure to maintain $\mathrm{O}_{2}$ consumption during anoxia are not simple. The first factor to be considered is the environmental temperature. When a man or an animal is exposed to a cold environment his rate

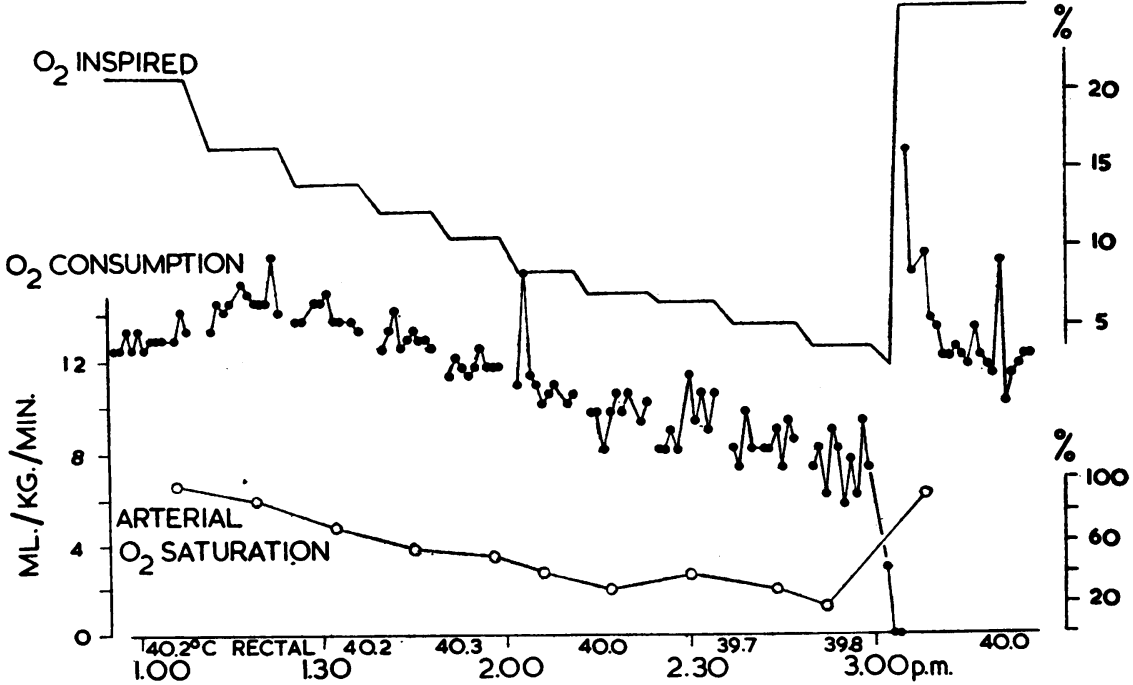

FIG. 4.-When the $\mathrm{O}_{2}$ content of the inspired air is progressively reduced in a newborn lamb maintained at the neutral temperature, there is a considerable fall in $O_{2}$ consumption (Cross, Dawes and Mott, 1959). of oxygen consump-

tion increases. He not only attempts to reduce heat loss by vasoconstriction in the skin, but he also spends more energy in an attempt to maintain his body temperature. On the other hand if he is exposed to a very warm environment he begins to pant, becomes restless, and once again his rate of oxygen consumption increases. There is therefore an intermediate range of environmental temperature at which oxygen consumption, at rest, is minimal. This is known as the neutral temperature. Small animals, such as mice and rats, when kept at their neutral temperature, show only a small fall in $\mathrm{O}_{2}$ consumption during anoxia, but at lower environmental temperatures the fall is considerable (Lintzel, 1931; Chevillard and Mayer, 1935; Blood, Glover, Henderson and d'Amour, 1949; Flückiger, 1956). Hill (1958) has done a particularly thorough analysis of this phenomenon on newborn kittens and adult guinea-pigs, and has shown in both that the extra $\mathrm{O}_{2}$ consumption which occurs on exposure to a less warm environment is particularly susceptible to oxygen lack. Fig. 5 demonstrates this phenomenon in a 60-day-old lamb. The $\mathrm{O}_{2}$ consumption at the start of the experiment, breathing air at an environmental temperature of $19^{\circ} \mathrm{C}$., was $120 \mathrm{ml}$./min. The environmental temperature was then lowered and $\mathrm{O}_{2}$ consumption increased to $190 \mathrm{ml} . / \mathrm{min}$. When the lamb was given $10 \% \mathrm{O}_{2}$ to breathe, instead of 'air, $\mathrm{O}_{2}$ consumption rapidly fell to $110 \mathrm{ml}$./min., i.e. just below what it had been before exposure to cold. When the oxygen content of the inspired air was raised, shivering began again and $\mathrm{O}_{2}$ consump- tion increased. The fall in $\mathrm{O}_{2}$ consumption during anoxia was just about equal to the increase on exposure to cold. This phenomenon is particularly easy to demonstrate in young animals or small animals, and one suspects that it is size, as much as youth, which is of importance.

There are other factors concerned with the inability of newborn animals to maintain their $\mathrm{O}_{2}$ consumption during anoxia. Firstly, $\mathrm{O}_{2}$ consumption falls if body temperature falls, and here small animals are particularly at a disadvantage because their heat capacity is low and their surface area relatively large. Secondly, in newborn lambs there is also a large fall in $\mathrm{O}_{2}$ consumption during anoxia, even when the lamb is at its neutral temperature and when the deep body temperature is well maintained (Fig. 4). This fall is easy to demonstrate in a lamb a few days after birth, when $\mathrm{O}_{2}$ consumption has increased from the foetal to the neonatal level (Fig. 6). But lambs which are 3 weeks old or more behave more like adults (Cross, Dawes and Mott, 1959). It would appear therefore that this is another phenomenon peculiar to the transition from foetal to neonatal life.

In summary then, $\mathrm{O}_{2}$ consumption falls in anoxic newborn animals for a variety of reasons. Some of these are related to body size; it is by no means certain that immaturity of the physiological mechanisms can be blamed. And now, you may well ask, is the newborn animal the worse or the better off for its ability to dispense with part of its normal $\mathrm{O}_{2}$ requirement? In so far as its body 


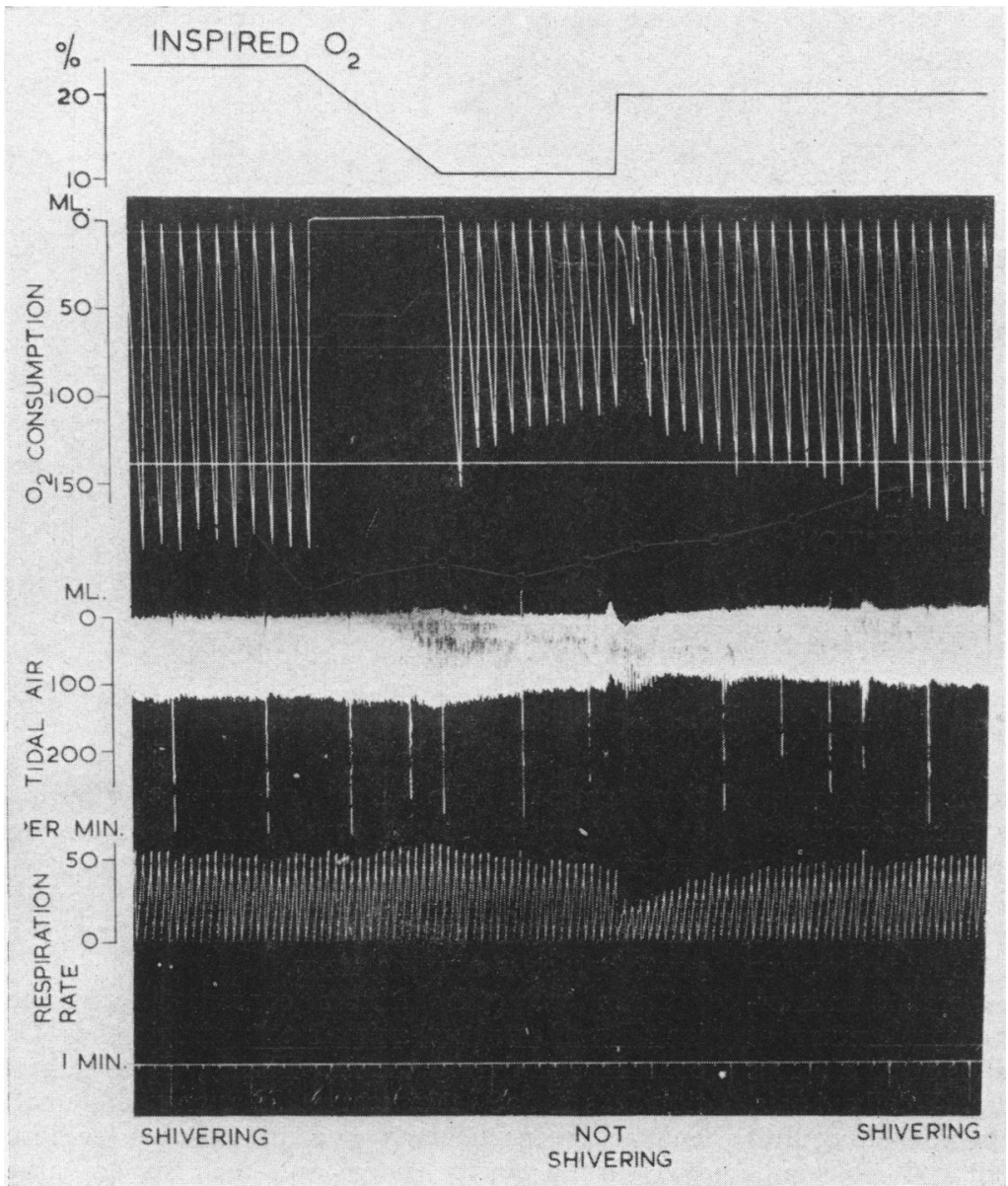

Fig. 5.-A lamb was placed in a low environmental temperature, in which it shivered. When the $\mathrm{O}_{2}$ content of the inspired air was lowered, shivering ceased and $\mathrm{O}_{2}$ consumption fell; when it was raised, $O_{\text {. }}$ consumption increased and shivering reappeared (Cross, Dawes and Mott, 1959).

temperature falls, I would surmise that it is worse off, but we still really do not know for sure. It is dangerous to assume that such mechanisms have a purpose. I think we should be satisfied for the moment to understand the mechanisms.

\section{Respiration and Partial Oxygen Lack in the Newborn}

We now come to a consideration of respiratory behaviour in the newborn, and the response to partial oxygen lack. During the past decade there have been several investigations of the control of respiration in the newborn infant. Dr. Kenneth Cross showed that when a baby was given $15 \% \mathrm{O}_{2}$ to breathe, it reacted by hyperpnoea which lasted only a few minutes. This was unexpected, because in adults the hyperpnoea is maintained. Cross and Oppé (1952) concluded that the hyperpnoea was due to stimulation of the chemoreceptors and that the failure to maintain hyperpnoea was due to depression of the respiratory centre by oxygen lack. That seemed the only possible interpretation, but it was rather surprising that such a relatively small degree of anoxia should cause respiratory depression. Another group of workers in the U.S.A. failed to observe hyperpnoea on giving low oxygen mixtures to newborn babies at all (Miller and Smull, 1955), a result which led them to believe that the chemoreceptor mechanisms were not functional after birth. This is, on the face of it, an even more surprising conclusion. One would have expected that anoxic stimulation of respiration would be well-developed in the newborn, above all else. Was it possible, then, that there were some other circumstances about the experiments which led to these unexpected observations?

One possible approach was to try and see under what circumstances the same responses could be obtained in experimental animals. The newborn rabbit was chosen for this purpose. A preliminary investigation showed that the Hering-Breuer respiratory reflexes, the carotid chemoreceptor reflex and the pulmonary deflation reflex were all present and active in the rabbit at birth. This conclusion was verified by section of the appropriate nervous pathways, for the reflexes then disappeared. I do not propose to go into the experimental details, but would emphasize that it is important to have reached the conclusion in one species at least (and the rabbit is born in a relatively immature state, with its eyes closed and unable to fend for itself) that the crucial respiratory reflexes are well established at birth.

When newborn rabbits were exposed to low 


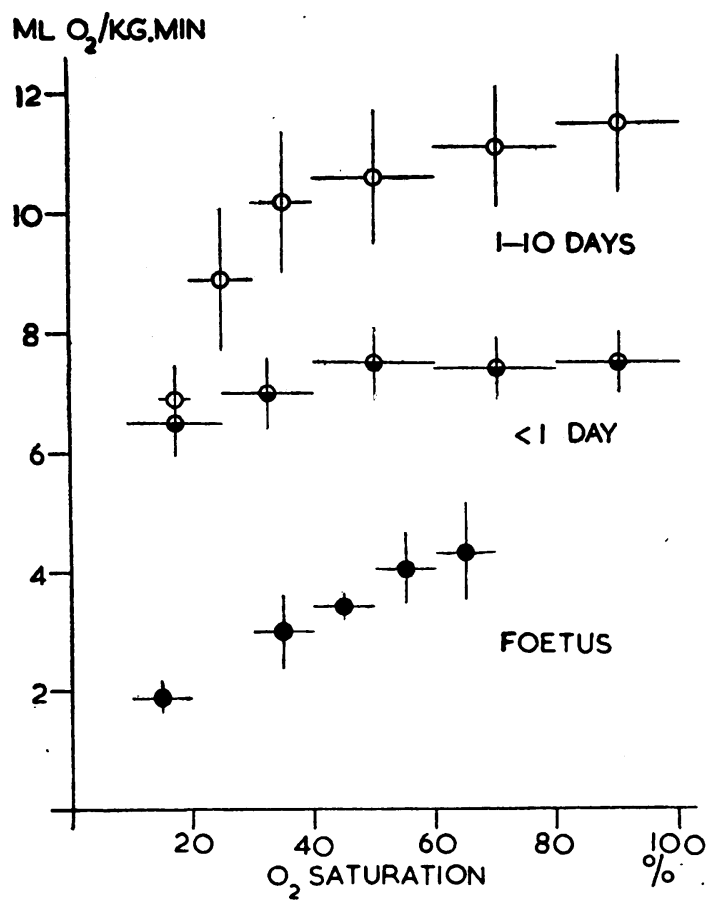

FIG. 6.-Diagram to show the behaviour of foetal and newborn lambs in response to anoxia. Ordinate, $\mathrm{O}_{22}$ consumption/unit body weight; abscissa, arterial $\mathrm{O}_{2}$ saturation. The vertical lines through each circle indicate the $95 \%$ confidence limits of the means, and the horizontal lines the range of the observations, all of which were made at the neutral temperature (Cross, Dawes and Mott, 1959).

oxygen mixtures at an environmental temperature above $30^{\circ} \mathrm{C}$. the rate and depth of breathing was increased, and this increase was well-maintained (Fig. 7). But at lower ambient temperatures there was only a transient increase, or even a decrease in the minute volume of breathing (Dawes and Mott, 1959a). Subsequent experiments suggest that this phenomenon occurs in both newborn rabbits and lambs when exposed to a temperature rather below the neutral range, that is to say, in conditions in which the rate of oxygen consumption has already increased in response to cold, but with only a trivial fall of deep body temperature. We do not know if these observations provide an explanation for the respiratory findings on human babies; they may do so, but only experiment will determine this. Meanwhile we may note that, in newborn animals: (1) There is evidence of a full range of respiratory reflexes at birth, at the neutral temperature. (2) If the environmental temperature is lowered below the neutral range, oxygen consumption normally increases, but then $(a)$ slight anoxia causes a considerable fall of oxygen consumption; and $(b)$ the hyperpnoea in response to anoxia is poorly maintained, or even absent altogether.

I am not sure whether we should be justified in concluding that it would be wise to maintain a newborn infant, who was suffering from respiratory difficulties, at the neutral temperature (i.e. a high environmental temperature), but I should not be at all surprised if this does not prove to be the safest procedure in the long run. Only observations on newborn infants will tell us this.

\section{The Task of the Circulation}

Next there is the question of autonomic control of the circulation after birth. In the past a number of observations have been widely quoted, which purport to show that the autonomic nervous system is, in one respect or another, either not functional, or barely functional at birth. Thus it has been concluded that the vasomotor reflexes were not developed in the newborn rabbit, kitten or puppy until some days or weeks after birth. However,
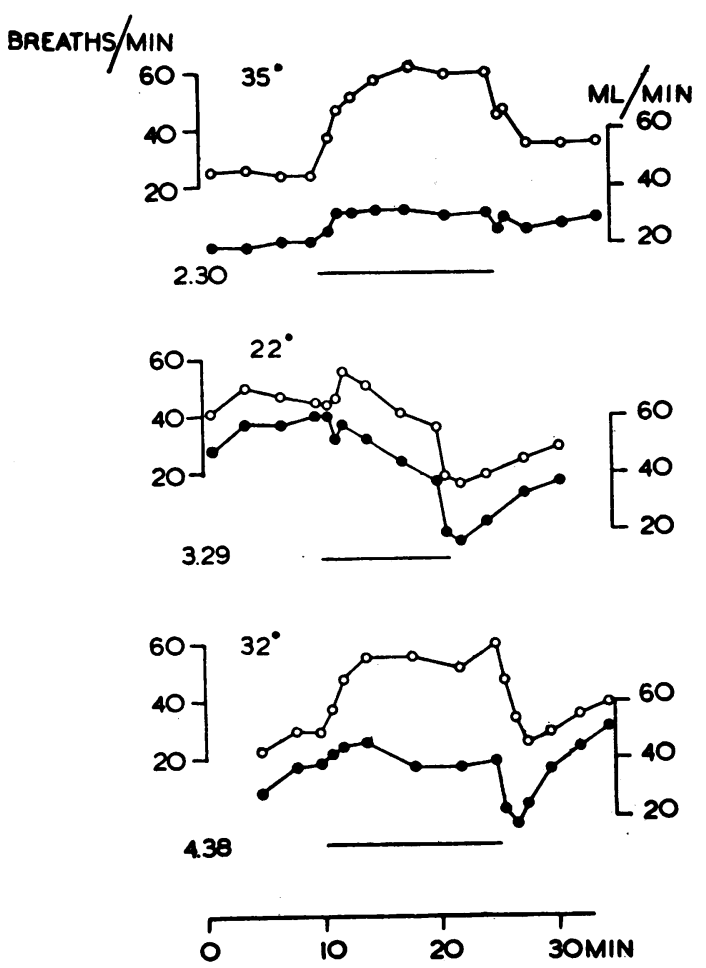

Fig. 7.-Rabbit 4 days old. Open circles respiratory rate; closed circles minute volume. During the periods indicated by the solid lines the rabbit breathed $11 \% \mathrm{O}_{2}$ instead of air. At an environmental temperature of $32-35^{\circ} \mathrm{C}$. the rabbit showed a maintained hyperpnoea in response to anoxia, but at $22^{\circ} \mathrm{C}$. the hyperpnoea was not maintained (Dawes and Mott, 1959a). 
closer and more critical examination of the experiments on which these conclusions are based show them to be inadequate, in many respects, by present day standards. To take a very simple example, Soltmann (1877) reported that stimulation of the peripheral end of the vagus did not slow the heart in a newborn rabbit; Kellogg (1927) found that it did sometimes, but not always. Admittedly newborn rabbits are rather small, and weigh only about $50 \mathrm{~g}$., but nevertheless with better instruments than were formerly available it is possible to show that vagal stimulation always slows the heart, and other evidence suggests that the vasomotor reflexes are present and functional. This may be regarded as a corollary of the evidence already quoted, that the respiratory reflexes are well established at birth in the rabbit.

What is equally important is the growing realization that the task with which the cardiovascular system of a newborn creature is faced is not the same, quantitatively, as that in an adult. Even after the foetal cardiovascular channels are completely closed, by a week or 10 days after birth, there are differences. The quantity of oxygen to be carried from the lungs to the tissues in each minute is greater, per unit body weight, than in the adult. Fig. 8 shows that cardiac output, per unit body weight, is greater in the newborn lamb than in the adult ewe. Thus a lamb weighing $10 \mathrm{~kg}$. may have a cardiac output of $31 . / \mathrm{min}$. while a ewe of $50 \mathrm{~kg}$. has a cardiac output of only $51 . / \mathrm{min}$. This is not wholly surprising, and it may be pertinent to recall that the heart rate of small animals is in general greater than that of large ones. The few measurements of foetal cardiac output so far available suggest that cardiac output increases after birth. And whereas the cardiac output of an adult sheep increases three to five fold during anoxia, that of lambs up to 60 days old shows little change. This is one of the most striking differences between the behaviour of young and adult sheep subjected to oxygen lack. It would have been tempting to conclude that autonomic control of the circulation was inadequately developed in the young lamb, were it not for the fact that cardiac output is already relatively so high (Fig. 8). There is little doubt that we have a great deal more to learn in this field, and there is a danger to be avoided of generalizing from one species. Unfortunately it is by no means easy to measure cardiac output on small animals.

\section{The Ability to Survive in the Total Absence of Oxygen}

There is another fascinating physiological attribute of very young animals which demands attention.
This is their ability to survive periods of total oxygen lack which far exceed those which kill adults of the same species. To my mind this is one of the most important aspects of neonatal physiology, in relation to the clinical problems which are in the forefront of our minds. It is a matter which is of crucial importance if it is believed that some, perhaps many, cases of cerebral palsy result from asphyxia at birth. It may also serve to explain some of the bizarre pathological appearances in the lungs of infants which have died from respiratory difficulties after

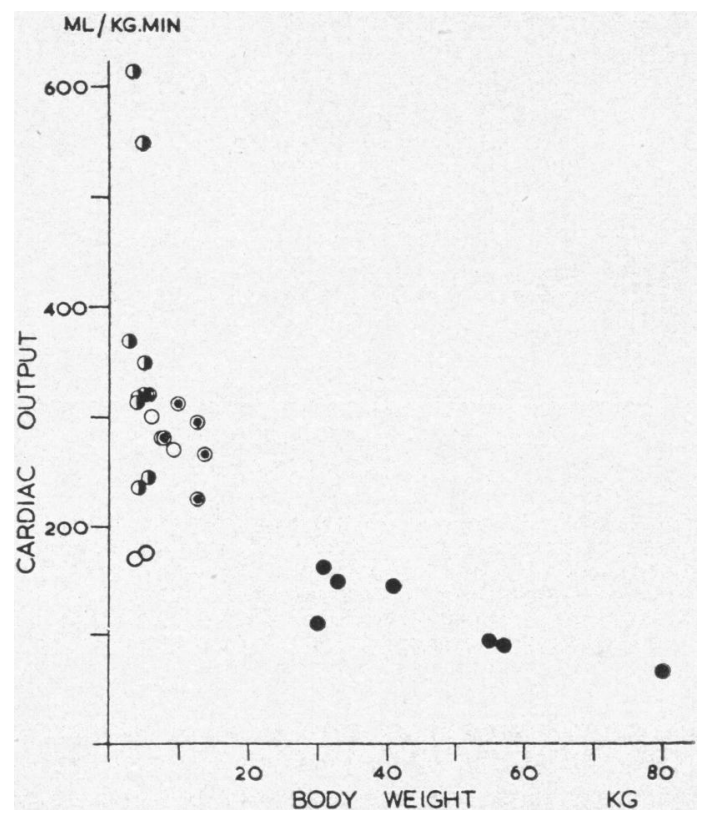

FIG. 8.-Cardiac output (Fick method) has been plotted against body weight for lambs less than 1 day old $(()), 2-12$ days old $(O)$, 20-60 days old $(\odot)$ and for adult sheep $(\odot)$, all while breathing air (Cross, Dawes and Mott, 1959).

birth, in that the heart can go on beating, and the lungs be expanded, in the presence of anoxia from which any adult would rapidly succumb.

It is strange that so little experimental work has been undertaken on this problem. The essential facts are well authenticated. Human babies have been delivered by caesarean section after the death of their mother and have survived. They have also survived prolonged periods of suffocation from various causes. When given $100 \%$ nitrogen to breathe, newborn rats live for as long as $\mathbf{5 0}$ minutes and kittens and puppies more than 20 minutes, while newborn guinea-pigs and lambs, which are more mature at birth, live for only seven to 10 minutes. Himwich, Bernstein, Herrlich, Chesler and Fazekas 
(1942) have shown that administration of iodoacetate, which blocks the enzyme systems responsible for glycolysis, reduces the survival time of young animals in anoxia to that of adults. It is evident that in such young animals energy is obtained during anoxia by breakdown of carbohydrate to lactic and pyruvic acids, and that it is by deriving this energy that the animal can survive. One of the difficulties about such studies is that newborn animals are either very small, or if they are

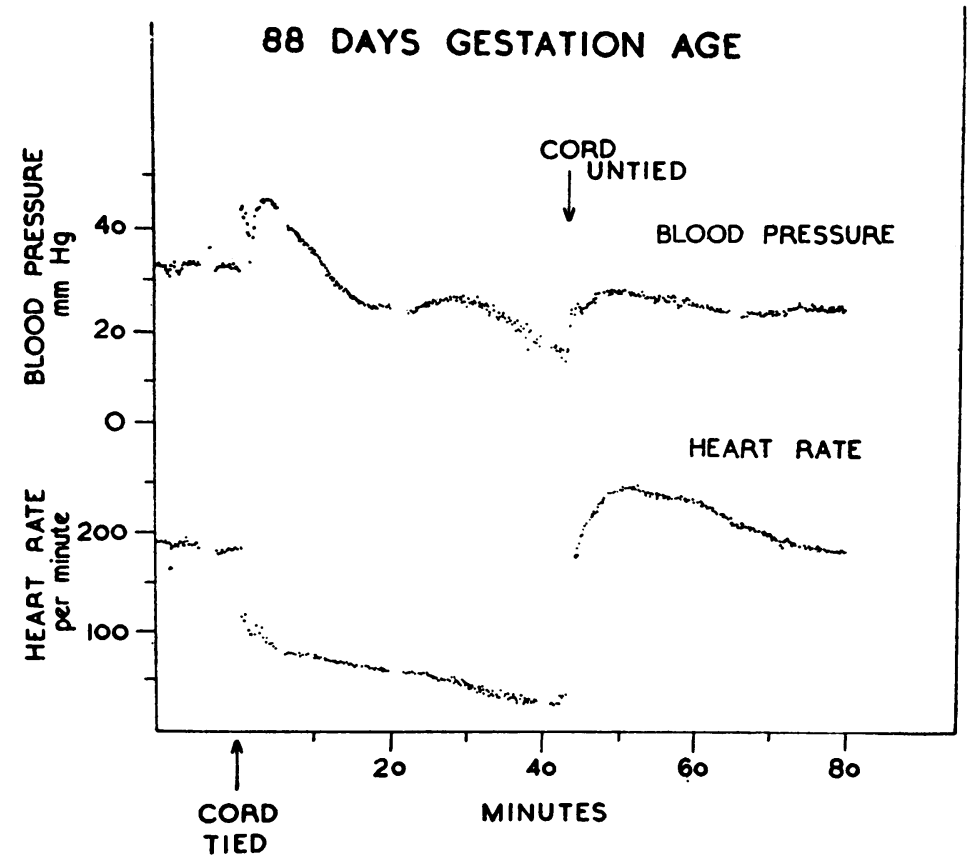

FIG. 9.-Foetal lamb of 88 days gestation age (term is 147 days). The umbilical cord was tied for 40 minutes and then untied, when blood pressure and heart rate recovered (Dawes, Mott and Shelley, 1959).

larger do not survive anoxia for long. It is therefore not easy to obtain serial blood samples and hence to study the biochemical changes during anoxia. However, foetal lambs, just over half-way through gestation, weighing $350-600 \mathrm{~g}$., are suitable subjects for this purpose. The umbilical cord may be tied for as long as $\mathbf{4 0}$ minutes, with apparently complete recovery when it is then untied (Fig. 9). During the period of anoxia carbohydrate appears and lactic acid accumulates in the blood, rising first rapidly and then more slowly. The $p \mathrm{H}$ of the blood begins to fall within one minute of tying the cord, and reaches $7 \cdot 0$ which is very low indeed, on the average by 10 minutes. The most remarkable feature of these experiments was that most of the carbohydrate loss appeared to be from the heart, which at this period of life has very large reserves. More mature foetal lambs had less carbohydrate in their ventricular muscle, and were able to withstand total anoxia for a shorter period of time. In newborn animals also there was a linear relationship between the carbohydrate concentration in the ventricles of the heart before asphyxia, and the duration of survival as timed to the last respiratory effort. This holds not only for rats at different ages from birth, but also for rabbits and guinea-pigs (Fig. 10).

There is certainly more to the problem than the cardiac carbohydrate, since it is well known that the decapitated head of a newborn rat will continue to make gasping movements for as long as 20 minutes. Yet these results are interesting for several reasons. Firstly, they lead to a broader understanding of the means whereby whole animals. survive total anoxia, and of the limitations thereto. It may be coincidence that there is a direct relation between the initial concentration of carbohydrate in the heart, and the duration of respiratory efforts; it may on the other hand be a causal relationship. As it is, these results make us consider once more whether it is the heart or the brain which usually succumbs first. There are a few tragic instances, in both children and adults, where the vegetative system has recovered from anoxia, but consciousness has never been regained. But if the cardiovascular system fails first then recovery is quite impossible. However effective ventilation is, oxygen cannot reach the brain if the output of the heart is inadequate, even though it may still be beating. It is therefore possible that the circulation may usually fail before there is irreversible damage to the brain. Secondly, these experiments must make us consider whether there are any means which can be employed to increase the duration of survival during total anoxia. Preliminary experiments have suggested that this is feasible; in some lambs the duration of survival has been doubled. But the optimal conditions have not yet been discovered, and at the present moment the method of treatment is hazardous. I do not want to indicate more than that 
the possibility exists. Thirdly, we must recognize that almost all babies are to some extent asphyxiated by the process of delivery, whatever the method and however expert the care. You have only to examine the published figures to recognize this. The mean figures for the arterial oxygen saturation in the umbilical cord are almost all less than $30 \%$, with an $\mathrm{O}_{2}$ partial pressure of only $8-16 \mathrm{~mm}$. $\mathrm{Hg}$. This is miserably low by any reasonable physiological standard, far less than the average for healthy foetal lambs. James, Weisbrot, Prince, Holaday and Apgar (1958) have recently published an interesting analysis of the biochemical changes in the blood of normal babies after birth. There was a systematic rise in $p \mathrm{H}$ and in the 'buffer base', indicating a recovery from metabolic acidosis, consequent on asphyxia at or before birth. The conclusion is inescapable that almost every baby at birth has had its carbohydrate reserves somewhat depleted by glycolysis, and begins an independent life with a blood $p \mathrm{H}$ considerably below the optimal. It is not at all surprising that some of these infants breathe poorly after birth; it is just as well that most of them can still make

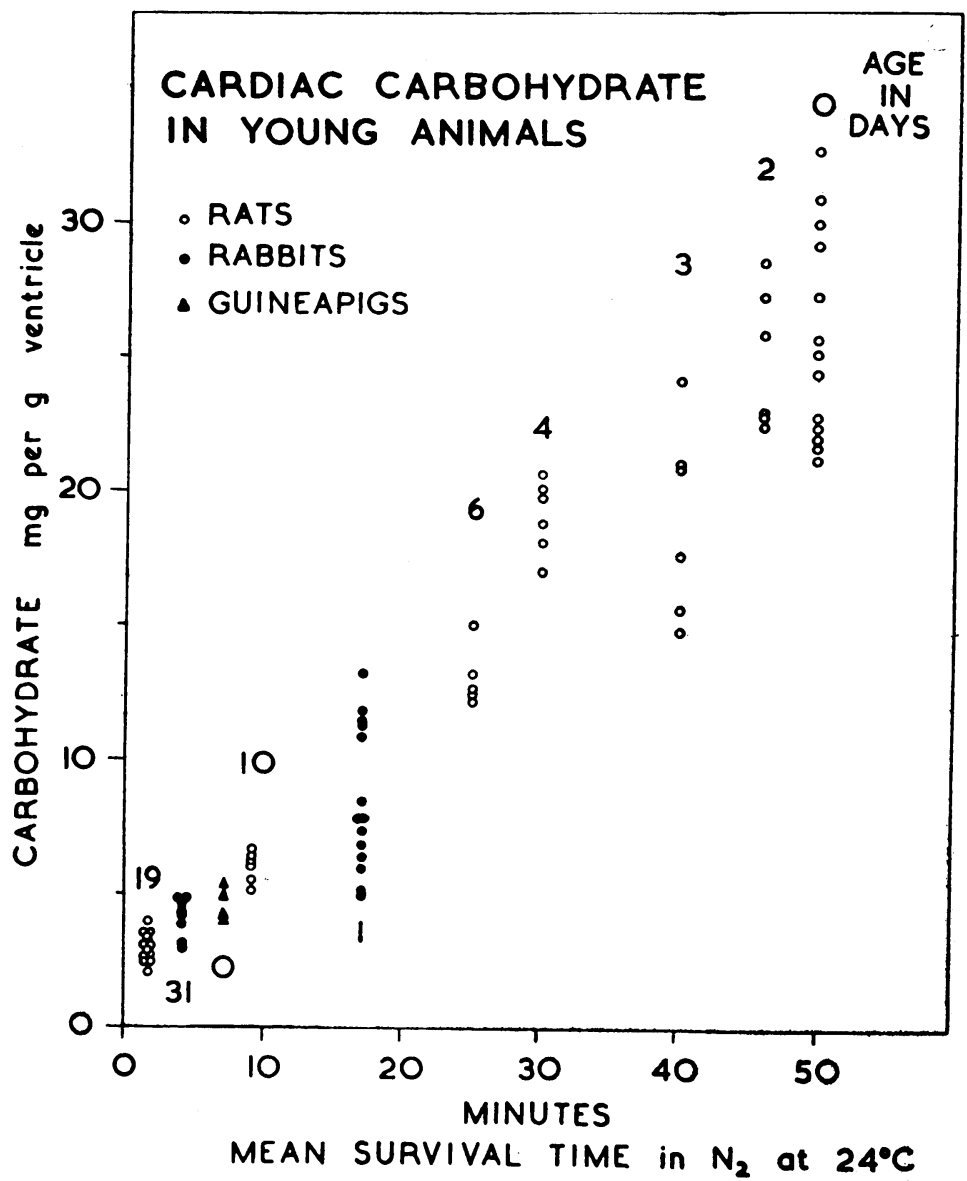

FIG. 10.-There is a roughly linear relationship between the mean survival time in nitrogen of young animals and the cardiac carbohydrate concentration before anoxia (Dawes, Mott and Shelley, 1959). respiratory efforts when there is no measurable oxygen in the arterial blood at all.

\section{Conclusion}

These animal experiments suggest that there is more to the newborn than at first appeared. He is neither a miniature replica of the adult, nor is he entirely helpless. He is not a weak creature, poorly endowed with the mechanisms which are required to maintain a constant internal environment.

A newborn animal is not only young, it is also small, compared with an adult of the same species, and it is growing rapidly. It is now evident that there is still something to be learnt about the way in which small animals, irrespective of youth, react to changes in their environment. Some of the reactions which were first thought of as characteristic of newborn creatures have been observed in adults (of other species) which are small in size. We should therefore be chary of concluding that any physiological mechanism in a newborn baby is immature, or underdeveloped, unless there are compelling reasons for doing so. McCance and Widdowson (1956) have provided an interesting example of this principle by showing that, because of their rapid growth, newborn piglets convert $90 \%$ of the nitrogen they ingest in a full diet into body protein. Hence the kidney does not need to be able to secrete more than a limited amount of urea. The kidney may be 'immature' by adult standards, but it is fully capable of doing the job it normally needs to do. Hence rapid growth rate, as well as size and environment, are most important factors to consider when assessing the physiological capabilities of a baby. We have seen that the course of the circulation in the newborn is in some respects 
different from that in the adult and that the responses to oxygen lack and to changes in environment temperature are also different. Yet the newborn creature is not passive; it is a complicated and highly integrated organism, and its behaviour deserves study for its own sake.

The biological mechanisms which I have endeavoured to describe have all presented problems in classical physiology. They could have been tackled with the methods which were available in 1928, when this Association was first founded, and when Still became its first President. There are several reasons why they have not been studied intensively. Some of these are of a technical nature; it is often tedious and sometimes difficult to perform experiments on small animals. But much more important has been the failure to realize that the problems even existed. With the realization that they do exist, and that nowadays more children die in the first seven days of life than during the next seven years, there is a challenge to further research that cannot be ignored.

I am grateful to the Journal of Physiology for permission to reproduce Figs. 3-10.

REFERENCES

Adams, F. H. and Lind, J. (1957). Pediatrics, 19, 431.
Amoıso E. C., Dawes, G. S. and Mott. J. C. (1958). Brit. Heart J., $20,92$.

Barclay, A. E. Franklin, K. J. and Prichard, M. M. L. (1944). The Foetal Circulation and Cardiovascular System, and the Changes Foetal Circulation and Cardiovascular System, and the Changes

that they Undergo at Birth. Blackwell, Oxford.
Barcroft, J. (1946). Researches on Pre-natal Life. Blackwell, Oxford. Blood, F. R., Glover, R. M., Henderson, J. B. and d'Amour, F. E. (1949). Amer. J. Physiol., 156, 62.

Burnard, 乏.. D. (1958). Brit. med. J., 1, 806.

Chevillard. L. and Mayer, A. (1935). Ann. Physiol. Physicochim. biol., 11, 225 .

Condorelli, M., Dagianti, A.. Polosa, C. and Giuliano, G. (1957). Atti del XIX Congresso della Società Italiana di Cardiologia, p. 165 .

Cordier D. and Mayer, A. (1935). Ann. Physiol. Physicochim. biol., 11, 199.

Cross, K. W., Dawes, G. S. and Mott, J. C. (1959). J. Physiol. (Lond.)., 146, 516.

— and Oppé, T. E. (1952). Ibid., 117, 38.

- Tizard, J. P. M. and Trythall, D. A. H. (1955). Ibid., 129, 69P.

二, Tizard, J. P. M. (1957). Acta paediat. (Uppsala), 46, 265

Dawes, G. S. and Mott, J. C. (1959a). J. Physiol.'(Lond.), 145, 85. - (1959b). Ibid., 146, 295.

Flic and Widdicombe, J. G. (1955). Ibid., 128, 344.

Flückiger, E. (1956). Helv, physiol. pharmacol. Acta, 14, 369.

Gorlin, R. and Lewis, B. M. (1954). J. appl. Physiol., 7, 180. 169.

Harrison, T. R. and Blalock, A. (1927) Amer.
Hill, J. R. (1958). J. Physiol. (Lond.), 143, 64P.

Hill, J. R. (1958). J. Physiol. (Lond.), 143, 64P.
Himwich, H. E., Bernstein, A. O., Herrlich, H., Chesler, A. and

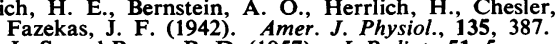

James, L. S. and Rowe, R. D. (1957). J. Pediat., 51, 5.

, Weisbrot, I. M., Prince, C. E., Holaday, D. A. and Apgar, V (1958). Ibid., 52, 379.

Kellogg, H. B. (1927). Proc. Soc. exp. Biol. (N.Y.), 24, 839.

Lind, J. and Wegelius, C. (1954). Cold Spr. Harb. Symp. quant. Biol., 19. 109.

Lintzel, W.' (1931). Pfüg. Arch. ges. Physiol., 227, 693.

McCance, R. A. and Widdowson, E. M. (1956). J. Physiol. (Lond.), 133, 373.

Miller, H. C. and Smull, N. W. (1955). Pediatrics, 16, 93.

Mount, L. E. (1958). J.'Physiol. (Lond.), 142, 57P.

Rowe, R. D. and James, L. S. (1957). J. Pediat., 51, 1

Soltmann, O. (1877). Jb. Kinderheilk., 11, 101.

Weisbrot, I. M., James, L. S., Prince, C.'E., Holaday, M. D. and Apgar, V. (1958). J. Pediat., 52, 395. 